\title{
CORRECTIONS
}

\section{First seizures in adults}

In this Clinical Review by Heather Angus-Leppan, an error occurred in the section "What investigations are needed after a first seizure in the acute setting?" (BMJ 2014;348:g2470, doi:10. 1136/bmj.g2470). The second sentence should read, "Electrocardiography [not Electroencephalography] is mandatory in anyone with loss of consciousness, as syncope of any cardiac cause may present as a secondary hypoxic seizure, and potentially fatal arrhythmias, particularly long QT syndromes (Brugada syndrome), will otherwise be missed."

Cite this as: BMJ 2014;348:g2977

๑ B BMJ Publishing Group Ltd 2014 